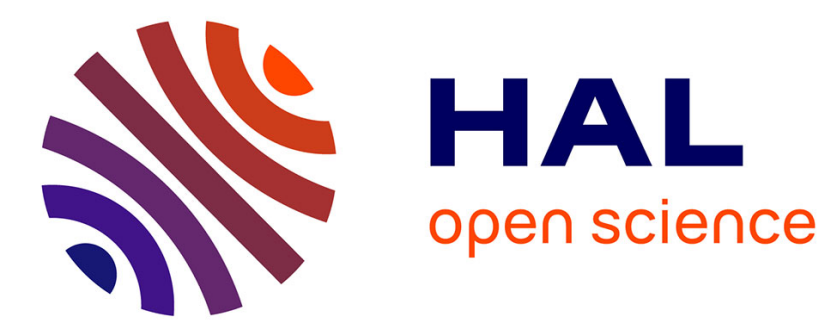

\title{
Dust density influence on complex plasma decay
}

Lénaïc Couëdel, Alexander A. Samarian, Maxime Mikikian, Laifa Boufendi

\section{To cite this version:}

Lénaïc Couëdel, Alexander A. Samarian, Maxime Mikikian, Laifa Boufendi. Dust density influence on complex plasma decay. Fifth International Conference on the Physics of Dusty Plasmas, May 2008, Ponta Delgada, Azores, Portugal. pp.185, 10.1063/1.2996829 . hal-00328136

\section{HAL Id: hal-00328136 \\ https://hal.science/hal-00328136}

Submitted on 9 Oct 2008

HAL is a multi-disciplinary open access archive for the deposit and dissemination of scientific research documents, whether they are published or not. The documents may come from teaching and research institutions in France or abroad, or from public or private research centers.
L'archive ouverte pluridisciplinaire HAL, est destinée au dépôt et à la diffusion de documents scientifiques de niveau recherche, publiés ou non, émanant des établissements d'enseignement et de recherche français ou étrangers, des laboratoires publics ou privés. 


\title{
Dust density influence on complex plasma decay
}

\author{
L. Couëdel*, ${ }^{*}$, A.A. Samarian*, M. Mikikian ${ }^{\dagger}$ and L. Boufendi ${ }^{\dagger}$ \\ * School of Physics, The University of Sydney, NSW 2006 ,Australia \\ ${ }^{\dagger}$ GREMI, CNRS/Université d'Orléans, 14 rue d'Issoudun, BP6744, 45067 Orleans Cedex 2, \\ France
}

\begin{abstract}
In this paper, the influence of dust particles on the plasma losses in a complex plasma afterglow is studied. It is shown that the dust particles can drastically shorten the plasma loss time by absorption-recombination onto their surfaces. The dust particle absorption frequency increases with the dust density but the dependence is not linear for high dust density. Finally, the possible use of dust absorption frequency measurements as a diagnostics for complex plasmas is mentioned and supported by comparison to existing experimental data.
\end{abstract}

Keywords: Dust particles, afterglow, complex plasma

PACS: 52.27.Lw

Complex plasmas are ionized gases containing charged dust particles. Dust particles are charged due to their interactions with the surrounding plasma ions and electrons [1]. When a discharge is switched off, the dust particles will act as a sink for the electrons and the ions as absorption-recombination can occur on the dust particle surfaces. Thus, the dust particles can drastically shorten the plasma loss time.

The dust particle absorption time $\tau_{Q}$ can be written as [2]:

$$
\tau_{Q}^{-1}=\pi r_{d}^{2} n_{d} v_{T i}\left(1+\left(T_{e} / T_{i}\right) \varphi\right)
$$

where $\varphi$ is the dimensionless dust surface potential which can be linked do the dust charge number $Z_{d}$ by: $\varphi=Z_{d} e^{2} / 4 \pi \varepsilon_{0} r_{d} k_{B} T_{e}$. When the dust density increases, the electron and ion densities start to deviate from each other and the Havnes parameter $P_{H}=Z_{d} n_{d} / n_{i}$ increases. Consequently, the dust surface potential follows [1]:

$$
\left(\frac{T_{i}}{T_{e}} \frac{m_{e}}{m_{i}}\right)^{1 / 2}\left(1+\frac{T_{e}}{T_{i}} \varphi\right) \exp (\varphi)=1-P_{H}
$$

For low dust density, the dust particle absorption time can be approximated by [2]:

$$
\tau_{Q}^{-1} \simeq \pi r_{d}^{2} n_{d} v_{T i}\left(1+\frac{T_{e}}{T_{i}} \varphi_{0}\right)-\pi r_{d}^{2} n_{d}^{2} v_{T i} \cdot \frac{T_{e}}{T_{i}} \frac{4 \pi \varepsilon_{0} r_{d} k_{B} T_{e}}{e^{2}} \frac{\varphi_{0}}{n_{i}}
$$

where $\varphi_{0}$ is the dimensionless surface potential of an isolated dust particle. The dust particle absorption time is not inversely proportional to the dust density. Indeed when the dust density is high the dust surface potential is lower and the dust particle absorption time is increased compared to the value it would have if the dust particles can be considered as isolated. The exact numerical solutions of the dust particle absorption time (Eqs.1-2) is presented in Fig.1(Left) and compared to the approximate solution (Eq.3). 
In Fig.1, the absorption frequency $\tau_{Q}^{-1}$ has been calculated for $n_{i}=10^{8} \mathrm{~cm}^{-3}, T_{e}=$ $0.3 \mathrm{eV}$ (close to experimental values of Ref.[3]) and a dust particle radius of $r_{d}=$ $10 \mu \mathrm{m}$. For low dust densities the dust absorption frequency $\tau_{Q}^{-1}$ is increasing linearly as expected. On the contrary, for high dust density the absorption time $\tau_{Q}^{-1}$ deviates from linearity. The exact solution and the first order approximation are in agreement even though some small discrepancies are observed at high dust density.

In Eq.3, there are only a few parameters to know $\left(T_{e}, T_{i}, r_{d}, \varphi_{0}\right.$ and $\left.n_{i}\right)$. Consequently, it is possible to use the measurement of the absorption frequency in the afterglow of a complex plasma in parallel with other diagnostics to deduce some important parameters of the plasma. For example, in Ref.[3], the dust particle absorption frequency has been measured in the afterglow of a linear pulsed discharge. Their experimental results are fitted using Eq.3 (Fig.1(Right)). The fit gives $T_{i} \simeq 0.042 \mathrm{eV},\left(T_{e} / T_{i}\right) \varphi_{0}=4.4$ and thus assuming $T_{i} \leq T_{e} \leq 5 T_{i}$ (depending when the measurement has been performed in the plasma afterglow), it gives $10^{7} \mathrm{~cm}^{-3} \leq n_{i} \leq 5 \cdot 10^{7} \mathrm{~cm}^{-3}$.

To conclude, it has been shown that the presence of dust particles can drastically shorten the plasma loss time and that the increase of the dust absorption frequency does not depend linearly on the dust particle density. Finally, by comparing our results with existing experimental data, the possible use of absorption frequency measurement as a diagnostic for complex plasma is mentioned.
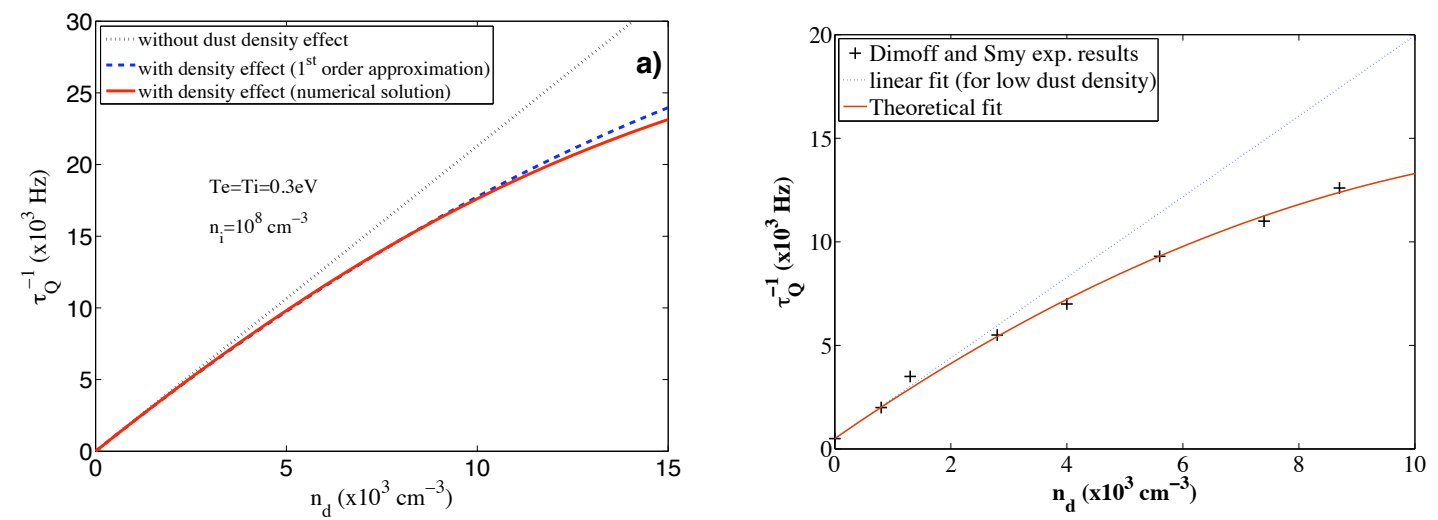

FIGURE 1. (Color Online) Left: Particle absorption frequency as a function of the dust density. with or without taking into account the dust density effect. Right: Fit of experimental results of Ref.[3] using the first order approximation (Eq.3).

\section{REFERENCES}

1. S. Vladimirov, K. Ostrikov, and A. Samarian, Physics and Applications of Complex Plasmas, Imperial Press, London, 2005.

2. L. Couëdel, M. Mikikian, A. Samarian, and L. Boufendi, Phys. Lett. A, submitted (2008).

3. K. Dimoff, and P. R. Smy, Physics Letters A 32, 13-14 (1970). 